\title{
A study to evaluate the pattern of microorganisms causing early post- operative wound infection in patients undergoing orthopaedic surgery with implant for closed fracture or disease in medical college and hospital, Kolkata
}

\author{
Subhankar Mukherjee ${ }^{1}$, Jayanta Mukherjee ${ }^{1}$, Sanjay Kumar ${ }^{2}$, Subarna Misra ${ }^{3}$, \\ Ranajit Bhatta $^{2}$, Manideepa Sengupta ${ }^{4}$
}

\begin{abstract}
${ }^{1}$ Department of Orthopedics, KPC Medical College and Hospital, Jadavpur, Kolkata, West Bengal, India ${ }^{2}$ Department of Orthopedics, Medical College and Hospital, Kolkata, West Bengal, India

${ }^{3}$ Department of Orthopedics, ICARE Institute of Medical Sciences and Research, Haldia, West Bengal, India

${ }^{4}$ Department of Microbiology, Medical College and Hospital, Kolkata, West Bengal, India
\end{abstract}

Received: 06 July 2020

Revised: 05 August 2020

Accepted: 07 August 2020

\section{*Correspondence:}

Dr. Subarna Misra,

E-mail: dr.smisra1977@gmail.com

Copyright: (C) the author(s), publisher and licensee Medip Academy. This is an open-access article distributed under the terms of the Creative Commons Attribution Non-Commercial License, which permits unrestricted non-commercial

\begin{abstract}
Background: For all orthopaedic surgical procedures with implant, infection at the operative site has always been recognized as a potential complication. The present study was done to evaluate the pattern of causative microorganisms in post-operative infection after orthopaedic surgery with implant in Medical College and Hospital, Kolkata.

Methods: This study was Institution based cross-sectional observational case study. Patients population were selected from the patients, who were admitted or came for follow up in the Department of Orthopaedics, who had undergone surgery with implant for close fracture and disease and developed early ( $<3$ months) post-operative wound infection The samples were collected and were sent to the Department of Microbiology, Medical College \& Hospital, Kolkata for isolation and identification of the microorganisms and their antimicrobial susceptibility were done.

Results: Maximum infections were detected and wound swabs were sent for culture in $2^{\text {nd }}$ week of surgery followed by 3 rd week. Only $10 \%$ ( 8 cases) had infection beyond 8 weeks. Plates with screws were used in 37 cases (46\%) and nails in 15 cases (19\%). It was been seen that infection in case of hip prosthesis were significant that is $8 \%$ (6 cases) which included four cases of hemiarthroplasty and two cases of total hip arthroplasty.

Conclusions: The data suggests that there is preponderance of Gram- negative infections in operated orthopaedic patients, but Staphylococcus aureus predominates the infectious agents as the sole pathogen. Klebsiella species and pseudomonas species are second and third most common pathogens respectively.
\end{abstract}

Keywords: Surgical site infections, Post-operative wound infection, Orthopaedic surgery, Implants, Microorganisms

\section{INTRODUCTION}

The surgical site infection (SSIs) after implant surgery is a disaster both for the patient and surgeon in orthopaedic practice. These SSIs may lead to increased antibiotic use, prolonged hospital stay, repeated debridement; prolong rehabilitation, morbidity and mortality especially orthopaedic procedures that involve prosthetic implants. ${ }^{1}$

There are increase requirements of joint replacement or internal fixation devices among elderly and trauma patients. Open reduction and internal fixation (ORIF) of fractures with implants and prosthesis has become the 
predominant modality of treatment of fractures in most trauma centres. ${ }^{2}$ Requirements of implants and prosthesis are because of the better understanding of the biomechanics of implantable materials and better functional outcome in these patients., ${ }^{2,3}$ Incidentally, studies have shown that there are association of postoperative wound infection (POWI) with those implants and prosthesis up to the range of 0.8 to $13 \%$, for both deep and superficial infections with attendant morbidity and cost. $^{3-7}$ This category of patients is particularly vulnerable because ORIF interferes with the blood supply to the bones and implants are foreign bodies, which provide surfaces for bacterial adherence. ${ }^{4}$

Despite considerable progress in prevention and treatment of implant-associated infection, the absolute number of patients with such infections is rising due to the lifelong risk for bacterial seeding on the implant and it is still a big challenge for orthopaedic practices. ${ }^{5}$ Study had revealed that SSIs may prolongs hospital stay on average for two weeks, doubles re-hospitalization rates, and costs can increase by over $300 \%$ in orthopaedic patients and this may leads to physical limitations and significant reductions in quality of life. ${ }^{6}$ Majority of cases eradication of microorganisms is difficult, which grow in biofilm and leads to pathogenesis of infection in fractures fixation devices. ${ }^{4}$ Till today the most common infecting organism in orthopaedic infection is Staphylococcus aureus. ${ }^{7}$

The presence of bacteria by itself does not constitute infection all the time. This hypothesis was accepted by the findings of one study of hardware removal in which $50 \%$ of cultures were positive in patients with no signs of symptoms or infection. ${ }^{8}$ Thus, there is an important distinction between colonization and infection. Understanding the factors that have changed the local or systemic environment with resultant bacterial infection is the key to effective prophylaxis, treatment, and improved outcomes in orthopaedic surgery.

Greater reduction in infection rate after implants have resulted with recent advances in infection prevention measures including pre-operative antimicrobial prophylaxis, improved sterilization techniques and aseptic measures, and routine post-operative antibiotic prophylaxis. We cannot afford SSIs after implants or prosthesis as because; infection at the operative site remains a potentially devastating, even fatal, outcome. ${ }^{9}$

In prosthetic joint infections, early infection is defined as manifestation of infection at the implant site during the first 3 months after surgery. Delayed infection is defined as manifestation of infection 3-24 months after surgery. Late infections defined as the manifestation of infection more than 2 years after surgery. ${ }^{11}$ This study is designed to know the different type of micro-organisms causing early (<3 month) post-operative infection in case of implant surgery and their sensitivity to type of antibiotics. The present study was done to evaluate the pattern of causative microorganisms in post-operative infection after orthopaedic surgery with implant in Medical College and Hospital, Kolkata.

\section{METHODS}

This study was Institution based cross-sectional observational case study. Patients population were selected from the patients, who were admitted or came for follow up in the Department of Orthopaedics of Medical College and Hospital, Kolkata, who had undergone surgery with implant for close fracture and disease and developed early ( $<3$ months) post-operative wound infection The samples were collected and were sent to the Department of Microbiology, Medical College \& Hospital, Kolkata for further processing. Isolation and identification of the microorganisms and their antimicrobial susceptibility were done. This study included 80 cases of early ( $<3$ months) post-operative wound infection where patients had undergone surgery with orthopaedics implant for closed fracture or disease (based on approx. number of cases with implant in a year and prevalence of infection). Sample collection was completed in one year (Feb 2014 to Jan 2015).

\section{Inclusion criteria}

Patients of all age group, both the sexes, having close fracture and/or disease, had undergone surgery with implant (including replacement and arthroscopic implants), developed post-operative wound infection and duration between operation and onset of infection less than 3 months were included.

\section{Exclusion criteria}

Patients having open fracture, pre-operative wound/infected wound, soft-tissue surgery, immunocompromised, diabetic patient and duration between operation and onset of infection more than 3 months were excluded.

\section{Wound surveillance}

The primary end-point of this study was three completed months following operation. Wounds were examined for infection on days three; seven, fourteen, at discharge and subsequent follow-up visits at the outpatient clinic or whenever patients complain of fever or burning sensation at operated site. The criteria for the diagnosis of postoperative wound infection were those used by the National Research Council of USA who defined POWI as "the presence of pus in a wound which has either discharged spontaneously or has to be released by the removal of sutures or re-opening the incision". ${ }^{10}$

Patients who had infection/suspicion of infection were taken to operation theatre and with all aseptic precautions wound were opened with the help of an assistant, material for culture and sensitivity were taken from deep parts of the wound with a sterile swab stick. The swab stick was 
put in a sterile test tube. Any patient who had developed postoperative wound infection, undergone pus microscopy, culture and sensitivity done. None of these patients had been previously catheterized. Aerobic and anaerobic cultures were carried out using blood and chocolate agar respectively on each infected wound specimen. Institutional ethics committee approval was taken and written informed consent was taken from patients and from parent or legal guardian of children for participation in the study.

All pus samples were cultured on 5\% sheep blood agar, and MacConkey agar. Incubation was done in incubator at 370 Celsius for 24 hours. The Isolation and identification of the microorganisms was done by standard microbiological procedures like (colony morphology, Gram staining, motility and biochemical tests). Data were entered in Microsoft excel sheet and analysed with GraphPad Prism 7 online. Descriptive statistics like mean and percentage was used.

\section{RESULTS}

A total number of 80 patients were included in this study. Wound swab was taken aseptically from infected surgical site in cases of early post-operative Orthopaedics surgeries with implants and after proper labelling sent to Department of Microbiology for culture and sensitivity during the period of study from February 2014 to January 2015. Table 1 shows sex distribution in this study, in which male were $45(56.25 \%)$ and female were $35(43.75 \%)$. Distribution of age in terms of interval shows more patients involved in $6^{\text {th }}$ and $5^{\text {th }}$ decades followed by $3^{\text {rd }}$ and $2^{\text {nd }}$ decades. This can be attributed to more operative intervention for fracture managements in these age groups.

Table 1: Characteristics of study participants $(n=80)$.

\begin{tabular}{|lll|}
\hline Characteristic & Number & Percentage $(\%)$ \\
\hline Male & 45 & 56.25 \\
\hline Female & 35 & 43.75 \\
\hline Age distribution & (yrs.) & \\
\hline $0-10$ & 5 & 6.25 \\
\hline $11-20$ & 7 & 8.75 \\
\hline $21-30$ & 10 & 12.5 \\
\hline $31-40$ & 11 & 13.5 \\
\hline $41-50$ & 16 & 20 \\
\hline $51-60$ & 22 & 27.5 \\
\hline $61-70$ & 7 & 8.75 \\
\hline $71-80$ & 2 & 2.5 \\
\hline Total & 80 & 100 \\
\hline
\end{tabular}

Table 2 shows distribution of cases according to time interval between injury and surgery which shows that maximum surgery done in $3^{\text {rd }}$ week of injury followed by $2^{\text {nd }}$ week. Seven cases were associated with either disease or deformity so time interval cannot be determined in those cases.
Table 2: Case distribution as per time gap between injury and surgery $(n=80)$.

\begin{tabular}{|c|c|c|}
\hline $\begin{array}{l}\text { Time interval } \\
\text { (days) }\end{array}$ & $\begin{array}{l}\text { Number of } \\
\text { cases }\end{array}$ & $\begin{array}{l}\text { Percentage } \\
(\%)\end{array}$ \\
\hline $0-7$ & 8 & 10 \\
\hline 8-14 & 18 & 22.5 \\
\hline $15-21$ & 27 & 33.75 \\
\hline $22-28$ & 8 & 10 \\
\hline 29-35 & 3 & 3.75 \\
\hline $36-42$ & 1 & 1.25 \\
\hline$>42$ & 8 & 10 \\
\hline Others ** & 7 & 8.75 \\
\hline Total & 80 & 100 \\
\hline
\end{tabular}

(**others: these cases were either diseases or deformity, so no question of time gap between injury and surgery.)

Maximum infections were detected and wound swabs were sent for culture in $2^{\text {nd }}$ week of surgery followed by 3rd week as shown in table 3 . Only $10 \%$ (8 cases) had infection beyond 8 weeks.

Table 3: Interval between surgery and detection of infection (collection of samples) $(n=80)$.

\begin{tabular}{|lll|}
\hline $\begin{array}{l}\text { Time interval } \\
\text { (days) }\end{array}$ & $\begin{array}{l}\text { Number of } \\
\text { cases }\end{array}$ & $\begin{array}{l}\text { Percentage } \\
(\%)\end{array}$ \\
\hline $\mathbf{0 - 7}$ & 2 & 2.5 \\
\hline $\mathbf{8 - 1 5}$ & 26 & 32.5 \\
\hline $\mathbf{1 6 - 2 1}$ & 20 & 25 \\
\hline $\mathbf{2 2 - 2 8}$ & 8 & 10 \\
\hline $\mathbf{2 9 - 3 5}$ & 2 & 2.5 \\
\hline $\mathbf{3 6 - 4 2}$ & 5 & 6.25 \\
\hline $\mathbf{4 3 - 4 9}$ & 5 & 6.25 \\
\hline $\mathbf{5 0 - 5 6}$ & 4 & 5 \\
\hline $\mathbf{5 5 6}$ & 8 & 10 \\
\hline Total & 80 & 100 \\
\hline
\end{tabular}

Table 4 shows distributions of implants and prosthesis used in selected cases and corresponding percentages. Plates with screws were used in 37 cases $(46 \%)$ and nails in 15 cases $(19 \%)$. It was been seen that infection in case of hip prosthesis were significant that is $8 \%$ (6 cases) which included four cases of hemiarthroplasty and two cases of total hip arthroplasty.

Table 4: Distribution of implants used.

\begin{tabular}{|ll|}
\hline Implants used & No. of cases $(\%)$ \\
\hline Plates & $37(46.25)$ \\
\hline Nails & $15(18.75)$ \\
\hline Screws/wires & $15(18.75)$ \\
\hline DHS/DCS & $6(7.5)$ \\
\hline Hip Prosthesis & $6(7.5)$ \\
\hline Arthroscopy & $1(1.25)$ \\
\hline Total & $80(100)$ \\
\hline
\end{tabular}


Among selected cases, infection in case of femoral implants was most common that was $24 \%(\mathrm{n}=19)$ as shown in table 5. It also included inter-trochantric, subtrochantric and all extra-articular fractures of femur. Humerus was second most common site $16 \%(n=13)$. Leg and forearm were third most common site; each $14 \%$ of cases. All Intra-articular operation including knee, hip, ankle, elbow, shoulder comprises $32.5 \% \quad(n=26)$ of infection among selected case.

Table 5: Distribution of cases as per sites of operation.

\begin{tabular}{|ll|}
\hline Site of operation & No. of cases $(\%)$ \\
\hline Femur & $19(23.75)$ \\
\hline Humerus & $13(16.25)$ \\
\hline Tibia & $11(13.75)$ \\
\hline Radius and Ulna & $11(13.75)$ \\
\hline Knee & $7(8.75)$ \\
\hline Hip & $6(7.5)$ \\
\hline Ankle & $6(7.5)$ \\
\hline Elbow & $6(7.5)$ \\
\hline Shoulder & $1(1.25)$ \\
\hline Intra-articular & $26(32.5)$ \\
Extra-articular & $54(67.5)$ \\
\hline Total & $80(100)$ \\
\hline
\end{tabular}

Table 6: Pattern of micro-organisms isolated.

\begin{tabular}{|lll|}
\hline Organisms & $\begin{array}{l}\text { Number } \\
\text { of isolates }\end{array}$ & $\begin{array}{l}\text { Percentage } \\
(\%)\end{array}$ \\
\hline Staphylococcus aureus & 32 & 40 \\
\hline Klebsiella sp. & 14 & 17.5 \\
\hline Pseudomonas aeruginosa & 12 & 15 \\
\hline Escherichia coli & 4 & 5 \\
\hline Acinetobacter baumannii & 2 & 2.5 \\
\hline Enterococcus sp. & 2 & 2.5 \\
\hline $\begin{array}{l}\text { Staphylococcus, } \\
\text { coagulase negative }\end{array}$ & 2 & 2.5 \\
\hline Citrobacter sp. & 1 & 1.25 \\
\hline Proteus mirabilis & 1 & 1.25 \\
\hline Proteus sp. & 1 & 1.25 \\
\hline Proteus vulgaris & 1 & 1.25 \\
\hline No growth & 10 & 12.5 \\
\hline Total & 80 & 100 \\
\hline
\end{tabular}

Most common offending micro-organisms isolated from early infection in post-operative surgical site in orthopaedics was Staphyloccus aureus (39\%) as depicted by table 6; followed by klebsiella species (17\%) and pseudomonas species (15\%). Overall Enterobacteracae family was $27 \% \quad(\mathrm{n}=22)$. Coagulase negative staphylococcus was contributed $2 \%$ of post-operative wound infection. Acinobacter and enterococcus species were two each only. In two specimens isolated organism were mixed type (in one it was staph. aureus and proteus mirabilis and in other it was pseudomonas and klebsiella sp). Significant portion (approx. 11\%, n=10) of cultures had negative outcome (no growth). It can be attributed to continuation of antibiotics even during infection.

\section{DISCUSSION}

The implantation of orthopaedic prostheses/trauma implants is an invasive surgical procedure with an increased risk of post-operative infections compared to non-implant-related orthopaedic interventions. Since the lifespan and quality of orthopaedic implants are gradually improving and more biomaterials are implanted every year, the prevalence of post-operative infections is expected to increase. ${ }^{11-13}$

These infections are usually caused by the exogenous or endogenous microorganisms that enter the operative wound during the course of surgery. ${ }^{14} \mathrm{~A}$ wide variety of aerobic and anaerobic species of bacteria may be present, either singly or in combination. The lowest infection rate (less than $2 \%$ ) followed clean operations, such as elective orthopaedic procedures, in which the possible sources of contamination were solely airborne or exogenous. The scenario of SSI is different in orthopaedic surgeries as compared to other surgeries in terms of use of implants, duration of surgery etc. which are important risk factor that accounts to higher infection rate in these surgeries.

In our study, male patients were $56 \%(n=55)$ and female $44 \%(n=35)$ and probably this can be attributed to more facture's incidence in male person. More affected age groups were 6 th decade and 5 th decade followed by $3^{\text {rd }}$ and $2^{\text {nd }}$ decade. This can be attributed to more operative approach in these age groups and more conservative approach in paediatrics and old patients. According to present results, positive culture was seen on majority of the studied patients $(89 \%)$, while in the study of Gomez et al reported positive cultures was $60 \% .{ }^{15}$ The finding of Zimmeli et al $2004^{16}$ was exactly the same us, that is $89 \%$.

The microbiology of post-operative wound infection in implants has changed very little over time except for the emergence of resistant organisms. ${ }^{17-24}$ Prevalence of isolates in our study were staphylococcus aureus, 39\% $(\mathrm{n}=32)$ followed by Klebsiella species $(17 \%)$ and pseudomonas species (15\%). Overall Enterobacteracae family have $27 \% \quad(\mathrm{n}=22)$. Coagulase negative staphylococcus and acinobacter species contributed two each in total isolates.

Staphylococcus aureus was frequently found in present study, followed by Klebsiella species and P. aeruginosa, which we assumed that these were the main nosocomial pathogens in our operating room. Present findings were in agreement with the extensive study of Arciola et al which reported staphylococci as the most prevalent organism and study of Mousa that reported $P$. aeruginosa as the significant isolated organism. ${ }^{25,26}$ However, this organism was the third most prevalent bacterium in present study. 
Staphylococcus aureus was the most commonly isolated micro-organism in this study accounting for 39\%. Our results are in accordance with the study of Benabdeslam et al wherein they also had isolated $S$. aureus as their most commonly infecting organism in $33.1 \%$ cases. ${ }^{27}$ It was similarly most common in various other reports worldwide. The relative rates however vary from centre to centre. At the National Orthopaedic Hospital Lagos, Onche found it accounted for $71.4 \%$ of his isolates while in Zaria, North Central Nigeria, Mbamali isolated staphylococcus aureus in $60 \%$ of patients while Classen et al in USA noted that it occurred in $16.3 \%$ of their cases. ${ }^{18,19,28}$ The picture was however different at Jos where Oguachuba found Proteus sp, to be the most common isolate with a rate of $41.9 \%$ followed by Staphylococcus aureus with $25.6 \% .^{29}$

In another study in India Agrawal et al found out that the most common infecting organism in their institute was $E$. coli (34.4\% cases) followed by Pseudomonas (26.1\% cases) and then $S$. aureus in $21.6 \%$ cases. This is in contrast to our study wherein we found $E$. coli and Pseudomonas each in $18.9 \%$ cases only. However, their study was a broad study dealing with all sorts of orthopaedic infections including bedsores, osteomyelitis, open fractures etc. This might be a reason for the difference in organism pattern obtained. ${ }^{30}$

\section{CONCLUSION}

The data suggests that there is preponderance of Gramnegative infections in operated orthopaedic patients, but Staphylococcus aureus predominates the infectious agents as the sole pathogen. Klebsiella species and pseudomonas species are second and third most common pathogens respectively. In case of Staph aureus, the most sensitive antibiotics are linezolid and vancomycin and in gram negative bacteria, it is imipenem and meropenem but these should not be used as initial drugs. It is worth mentioning here that, as we are entering in to the post-antibiotics era, it will be judicial to use antibiotic in post-operative wound infection only after proper culture and sensitivity report to prevent emergence of more and more resistant strains of pathogens.

\section{Funding: No funding sources}

Conflict of interest: None declared

Ethical approval: The study was approved by the institutional ethics committee

\section{REFERENCES}

1. Edwards C, Counsell C, Boulton C, Moran G. Early infection after hip fracture surgery, risk factors, costs and outcome. J Bone joint Surg. 2008;90:770-7.

2. Schatzker J. Principles of stable internal fixation. In: Schatzker J, Tile M (eds) The rationale of operative fracture Care. Spinger-Verlag, Berlin; 1996: 10-11.
3. Sisk DT. General principles of fracture treatment. In: Crenshaw AH (ed) Campbell's operative orthopaedics. Mosby, Missouri. 1987: 1551-61.

4. Zimmerli W, Trampuz A, Ochsner PE. Prostheticjoint infections. N Engl J Med. 2004;351:1645-54.

5. Husebye EE, Lyberg T, Opdahl H, Aspelin T, Støen RO, Madsen JE et al. Intramedullary nailing of femoral shaft fractures in polytraumatized patients- a longitudinal, prospective and observational study of the procedure-related impact on cardiopulmonary and inflammatory responses. Scand J Trauma Resusc Emerg Med. 2012;20:2.

6. Trampuz A, Zimmerli W. Diagnosis and treatment of infections associated with fracture fixation devices. Injury. 2006;37(2):S59-66.

7. Esterhai J, Gelb I. Orthopaedic infection. Ortho. Clin. North Am. 1991;22:503-10.

8. Moussa FW, Anglen JO, Gehrke JC, Christensen G, Simpsonet WA. The significance of positive cultures from orthopedic fixation devices in the absence of clinical infection. Am J Orthop. 1997;26(9):617-20.

9. Greene LR, Mills R, Moss R, Sposato K, Vignari M. An APIC guide. Guide to the elimination of orthopaedic surgical site infections. Washington, DC: APIC; 2010. Available at: http://www.apic.org/ Resource_/EliminationGuideForm/34e03612-d1e64214-a76b-e532c6fc3898/File/APIC-OrthoGuide.pdf. Accessed 22 April 2020.

10. Berard F, Gandon J. Post-operative wound infection: the influence of ultraviolet irradiation on the operating room and of various other factors. Ann Surg. 1964;160(2):1-192.

11. Zimmerli W, Lew PD, Waldvogel FA. Pathogenesis of foreign body infection. Evidence for a local granulocyte defect. J Clin Invest 1984;73:1191-1200.

12. Zimmerli W, Waldvogel FA, Vaudaux P, Nydegger UE. Pathogenesis of foreign body infection: description and characteristics of an animal model. J Infect Dis. 1982;146:487-97.

13. Montanaro L, Speziale P, Campoccia D, Ravaioli S, Cangini I, Pietrocola G, et al. Scenery of Staphylococcus implant infections in orthopedics. Future Microbiol. 2011;6:1329-49.

14. Nichols RL. Current Strategies for Prevention of Surgical Site infections. Curr Infect Dis Rep. 2004;6(6):426-34.

15. Gómez J, Rodríguez M, Baños V, Martinez L, Claver A, Ruiz J, et al. Infección de implantes osteoarticulares: factores pronósticos e influencia del tratamiento antibiótico prolongado en su evolución. Estudio prospectivo, 1992-1999 [Orthopedic implant infection: prognostic factors and influence of longterm antibiotic treatment on evolution. Prospective study, 1992-1999]. Enferm Infecc Microbiol Clin. 2003;21(5):232-6.

16. Zimmerli W, Trampuz A, Ochsner PE. Prostheticjoint infections. N Engl J Med. 2004;351(16):164554.

17. Olson M, O’Connor M, Schwartz M1. Surgical wound infection: a five-year prospective study of 
20,193 wounds at Minneapolis V.A. Medical Centre. Ann Surg. 1984;199:253-9.

18. Mbamali EI. Internal fixation of femoral shaft fractures at the Ahmadu Bello University Teaching Hospital Zaria. Nigerian Medical Practitioner. 1981;2:81-5.

19. Classen DC, Evans RS, Pestotnik SL, Horn SD, Menlove RL, Burke JP. The timing of prophylactic administration of antibiotics and the risk of surgical wound infection. N Engl J Med. 1992;326:281-5.

20. Efem SEE, Aja A, Inyang U. Surgical wound infection rate in Calabar University Teaching Hospital, Calabar. West Afr J Med. 1986;5:61-8.

21. Ojiegbe GC, Njoku-obi AN, Ojukwu J.O. Incidence and parametric determinants of post- operative wound infections in a University Teaching Hospital. Cent Afr J Med. 1990;36:63-7.

22. Cruse PJE, Ford R. The epidemiology of wound infection: a ten-year prospective study of 62, 939 wounds. Surg Clin Nor Am (Symposium on Surgical infection). 1980;60:20-40.

23. Moylan AJ, Kennedy VB. The importance of gown and drape barriers in the prevention of wound infection. Surg Gynecol Obstet. 1980;151:465-70.

24. Meakins JL. Guidelines for prevention of surgical site infection. In: Meakins JL (ed) Surgical infections: diagnosis and treatment. Scientific American Inc., New York. 1994;127-34.

25. Arciola CR, An YH, Campoccia D, Donati ME, Montanaro L. Etiology of implant orthopedic infections: A survey on 1027 clinical isolates. Int. J. Artif. Organs. 2005;28:1091-1100.

26. Mousa HA. Infection following orthopaedic implants and bone surgery. East Mediterr Health J. 2001;7:738-43.

27. Benabdeslam A, Berrady MA, Khermaz M, Mahfoud M, Berrada MS, Elyaacoubi M. Bacteriological profile of surgical site infection in orthopedic surgery about 142 cases. Int J Sci Technol Res. 2014;3:2717.

28. Onche II. Postoperative wound infection in implant surgery. Dissertation submitted to the National postgraduate Medical College of Nigeria. 2000:3443.

29. Oguachuba HN. Wound infection in the orthopaedictraumatology department of Jos University Teaching Hospital, Jos, Nigeria. Nigerian Med J. 1987;17:14751.

30. Agrawal AC, Jain S, Jain RK, Raza HK. Pathogenic bacteria in an orthopaedic hospital in India. J Infect Dev Ctries. 2008;2:120-3.

Cite this article as: Mukherjee S, Kumar S, Misra S, Bhatta R, Sengupta M. A study to evaluate the pattern of microorganisms causing early post-operative wound infection in patients undergoing orthopaedic surgery with implant for closed fracture or disease in medical college and hospital, Kolkata. Int J Res Orthop 2020;6:1204-9. 